\title{
PELATIHAN SHUTTLE TIME BULUTANGKIS DI SD NEGERI 91 PEKANBARU
}

\author{
Novri Gazali ${ }^{1 *}$, Romi Cendra ${ }^{1}$ \\ Jurusan Pendidikan Jasmani Kesehatan dan Rekreasi, Fakultas Keguruan dan Ilmu Pendidikan, \\ Universitas Islam Riau, Pekanbaru \\ Jl. Kaharuddin Nasution No. 113, Marpoyan Damai, Pekanbaru \\ *Penulis Korespodensi: novri.gazali@edu.uir.ac.id
}

\begin{abstract}
Abstrak
Provinsi Riau merupakan salah satu Provinsi yang sedang gencar-gencarnya melakukan pembinaan di berbagai cabang olahraga di antaranya adalah bulutangkis. Salah satu cara Pengurus PBSI (Persatuan Bulutangkis Seluruh Indonesia) Provinsi Riau meningkatkan dan mensosialisasikan olahraga bulutangkis yaitu dengan cara masuk ke sekolah-sekolah dan mengadakan kegiatan shuttle time di sekolah dasar. Shuttle time adalah suatu program kepelatihan bulutangkis untuk para GuruGuru olahraga sekolah dasar dan anak-anak usia dini dalam rangka pengembangan olahraga bulutangkis di sekolah dasar seluruh Indonesia. Pelatihan ini bertujuan untuk memasyarakatkan olahraga bulutangkis dan meningkatkan minat siswa dalam bermain bulutangkis, dan diharapkan dengan diadakannya kegiatan pengabdian masyarakat di SD Negeri 91 Rumbai Pekanbaru ini akan muncul bibit-bibit atlet bulutangkis masa depan khususnya dari Provinsi Riau. Kegiatan pengabdian masyarakat ini dilaksanakan di SD Negeri 91 Kecamatan Rumbai Kota Pekanbaru dengan peserta adalah Guru Penjaskes yang berjumlah 2 orang dan siswa SD Negeri 91 Pekanbaru yang berjumlah 22 orang. Materi yang akan disampaikan berisi tentang bagaimana belajar bulutangkis dengan benar dan bagaimana agar siswa-siswi di SD menyukai dan menyenangi olahraga bulutangkis. Metode yang diberikan berupa praktek dan tes keterampilan bermain bulutangkis siswa di SD Negeri 91 Pekanbaru..
\end{abstract}

Kata Kunci: Pelatihan Shuttle Time, Bulutangkis.

\begin{abstract}
Riau Province is one of the provinces that are incessant-incessant to coaching in various sports such as badminton. One of the Board's ways PBSI (Persatuan Bulutangkis Seluruh Indonesia) Riau Province improves and socializes badminton sport that is by way of entering to school and holding activity of shuttle time in elementary school. Shuttle time is a badminton coaching program for elementary school and early childhood sports teachers in order to develop badminton sport in elementary school all over Indonesia. This training is aimed to promote badminton sport and increase students' interest in badminton game, and it is expected that with community service activity in SD Negeri 91 Pekanbaru will emerge seeds of future badminton athletes especially from Riau Province. This community service activity was carried out in SD Negeri 91 Rumbai sub-district Pekanbaru with the participants were Teacher Penjaskes which amounted to 2 people and students SD Negeri 91 Pekanbaru City which amounted to 22 people. The material will be delivered about how to learn badminton properly and how to make the students in elementary school like and enjoy badminton sport. The methods given in the form of practice and test of badminton students play in SD Negeri 91 Pekanbaru.
\end{abstract}

Keywords: Shuttle Time Training, Badminton.

\section{PENDAHULUAN}

Pendidikan merupakan usaha orang dewasa secara sengaja menuju kedewasaan baik jasmani maupun rohani. Pada negara-negara yang baru berkembang, pendidikan merupakan hal yang sangat penting, karena baik tidaknya hasil pendidikan tersebut akan dapat berpengaruh pada maju atau tidaknya suatu bangsa dan negara. Indonesia adalah negara yang sedang berkembang dan sedang giat-giatnya dalam membangun di berbagai bidang, yang termasuk di dalamnya yaitu bidang pendidikan, jadi pendidikan adalah mutlak perlu dalm kehidupan, baik kehidupan seseorang, keluarga bahkan bangsa dan negara.

Salah satu bidang pendidikan nasional untuk menyiapkan manusia-manusia pembangunan yang sehat jasmani dan rohani. Pendidikan jasmani di sekolah dan olahraga dalam masyarakat jelas sangat besar artinya untuk pembangunan nasional dimana 
tujuan akhir dari berbagai bidang pembangunan tersebut adalah untuk manusia, juga dari manusia yang mana melaksanakan pembangunan perlu manusia yang sehat jamani dan rohani.

Pendidikan jasmani dan kesehatan adalah termasuk mata pelajaran di sekolah yang merupakan bagian tujuan hidup sehat menuju pertumbuhan jasmani, mental, sosial, dan emosional yang selaras serasi dan seimbang. Dari berbagai bentuk dan macammacam kegiatan pendidikan jasmani dan kesehatan di sekolah salah satunya yaitu cabang olahraga bulutangkis.

Bulutangkis merupakan salah satu olahraga yang terkenal di dunia. Olahraga ini menarik minat berbagai kelompok umur, berbagai tingkat keterampilan, dan pria maupun wanita memainkan olahraga ini di dalam atau di luar ruangan untuk rekreasi juga sebagai ajang persaingan. Bulutangkis merupakan olahraga yang dimainkan dengan menggunakan net, raket dan suttlecock dengan teknik pemukulan yang bervariasi, mulai dari yang relatif lambat hingga yang sangat cepat disertai dengan gerakan tipuan (Subardjah, 2001.3).

Menurut Subardjah, (2001:13), permainan bulutangkis merupakan permainan yang bersifat individual yang dapat dilakukan dengan cara satu orang melawan satu orang atau dua orang melawan dua orang. Permainan ini menggunakan raket sebagai alat pemukul dan shuttlecock sebagai objek pukul, lapangan permainan berbentuk segi empat dan dibatasi oleh net untuk memisahkan antara daerah permainan sendiri dan daerah permainan lawan. Sedangkan menurut Grace (1996:1) permainan bulutangkis merupakan salah satu cabang olahraga yang terkenal di dunia. Olahraga ini menarik minat berbagai kelompok umur, berbagai tingkat keterampilan, baik pria maupun wanita.

Tujuan permainan bulutangkis adalah berusaha untuk menjatuhkan shuttlcock dan berusaha agar lawan tidak dapat memukul kok dan menjatuhkannya di daerah permainan sendiri, (Donnie, 2009:3). Pada saat permainan berlangsung, masing-masing pemain harus berusaha agar kok tidak menyentuh lantai di daerah permainan sendiri. Apabila kok jatuh atau menyangkut di net maka permainan terhenti. Permainan bulutangkis mempunyai keunikan yang tidak dipunyai oleh cabang olahraga lainnya. Adapun keunikan tersebut antara lain: (1) alat yang digunakan sangat ringan, (2) nuansa penggunaan kekuatan paling lengkap, (3) mampu mematikan lawan dengan kekuatan mendekati nol, (4) memenuhi kebutuhan aktualisasi diri, (5) keterampilan gerak badminton mudah ditransfer ke dalam cabang olahraga lainnya, (6) filosofi kehidupan, (7) nilai kebugaran jasmani, (8) nilai bisnis yang tinggi.

Permainan bulutangkis merupakan permainan yang membutuhkan kemampuan fisik yang baik, kemampuan teknik, taktik dan strategi bertanding yang baik. Permainan ini bertujuan untuk mencetak poin dan mencegah lawan untuk mencetak poin. Kemampuan pemain sangat dipengaruhi oleh Penguasaan fisik, teknik, taktik dan starategi, yaitu: a) Fisik

Kemampuan fisik yang baik akan mendorong pencapaian kemahiran gerakan-gerakan dalam permainan bulutangkis (Muhajir (2006:24). Bentuk permainannya mengutamakan pukulan rally yang didasarkan pada daya tahan dan keuletan pemain. Yang diutamakan adalah selalu bertahan terhadap serangan lawan karena membutuhkan fisik dan daya tahan tubuh yang kuat serta kemauan yang panjang menyerah untuk mengejar ke mana arah shuttlecock.

\section{b) Teknik}

Muhajir (2004:102) menyatakan bahwa pola permainan yang diutamakan adalah mendalami dan mengulangi teknik pukulan dan cara melakukan tipuan. Dalam melakukan tipuan dilakukan dengan cara mengelabuhi penafsiran pihak lawan seperti akan memukul ke arah depan tetapi pelaksanaannya dilentingkan sehingga shuttlecock mengarah ke belakang lapangan lawan.

c) Taktik

"Taktik yang mungkin dapat dimanfaaatkan dengan baik oleh kebanyakan pemain adalah: (1) harus siap untuk mengubah cara bermain bila ketinggalan nilai, (2) jangan mengubah cara bermain bila menang, (3) kembangkan naluri membunuh dan kalahkan lawan secepat mungkin, (4) hindari bermain dengan gaya lawan, (5) percaya pada kemampuan jasmani sendiri, (6) kembangkan kemampuan untuk dapat memusatkan perhatian dan selalu berfikir dalam bertanding". (Abdoellah, 1981)

\section{(d) Strategi Dasar}

"Strategi dasar adalah memaksa lawan maju dan mundur mengejar shuttlecock sampai lawan melakukan pukulan yang lemah atau membuat kesalahan dan mengembalikannya dengan pukulan smash agar memperoleh nilai”. (Abdoellah, 1981). Dalam bermain selalu terjadi perubahan dari keadaan menyerang dan bertahan. Pukulan serang adalah pukulan yang diarahkan ke lantai atau ke bawah seperti smash. Pukulan bertahan adalah pukulan yang diarahkan ke atas lawan menyerang, seperti lob tinggi, servis tinggi. Pada permulaan bermain bulutangkis pemain harus menentukan tipe permainan yang akan dilakukan. Apakah tipe permainan menyerang, bertahan atau gabungan.

Permainan bulutangkis termasuk olahraga murah, merakyat atau sudah memasyarakat, artinya permainan bulutangkis biasa dimainkan dari golongan atas sampai gulongan-golongan bawah, dari pelosok pedesaan sampai perkotaan, masyarakat dan sekolah. Permainan bulutangkis di sekolah tidak asing lagi, karena sudah banyak dijumpai pertandinganpertandingan bulutangkis sekolah seperti O2SN.

Provinsi Riau merupakan salah satu Provinsi yang sedang gencar-gencarnya melakukan pembinaan di berbagai cabang olahraga di antaranya adalah bulutangkis. Salah satu cara Pengurus PBSI (Persatuan Bulutangkis Seluruh Indonesia) Provinsi Riau 
meningkatkan dan mensosialisasikan olahraga bulutangkis yaitu dengan cara masuk ke sekolahsekolah dan mengadakan kegiatan shuttle time di sekolah dasar.

Shuttle time adalah suatu program kepelatihan bulutangkis untuk para Guru-Guru olahraga sekolah dasar dan anak-anak usia dini dalam rangka pengembangan olahraga bulutangkis di sekolah dasar seluruh Indonesia, dengan tujuan untuk meningkatkan minat guru-guru Penjaskes dan siswa SD menyukai olahraga bulutangkis (Yusuf, 2013). Shuttle time pertama kali diadakan di dunia pada tahun 2011 dan secara resmi diluncurkan BWF (Badminton World Federation) pada tahun 2012.

\section{BAHAN DAN METODE}

Kegiatan pengabdian masyarakat ini dilaksanakan di SD Negeri 91 Kecamatan Rumbai Kota Pekanbaru dengan peserta adalah Guru Penjaskes yang berjumlah 2 orang dan siswa SD Negeri 91 Rumbai Kota Pekanbaru yang berjumlah 22 orang.

Materi yang akan disampaikan berisi tentang bagaimana belajar bulutangkis dengan benar dan bagaimana agar siswa-siswi di SD menyukai dan menyenangi olahraga bulutangkis. Metode yang diberikan berupa praktek langsung ke lapangan, membuat berbagai macam permainan yang menyenangkan dan melakukan tes keterampilan bulutangkis untuk siswa-siswi SD Negeri 91 Pekanbaru. Program kegiatan ini dilaksanakan di SD Negeri 91 Pekanbaru, selama dua hari, yaitu pada tanggal 12 Agustus - 13 Agustus 2016.

Tabel 1. Kegiatan Pelatihan Shuttle Time Bulutangkis

- Kegiatan Hari Pertama

\begin{tabular}{|c|c|c|c|}
\hline No & Waktu & Kegiatan & Pelaksana \\
\hline 1 & $1 \mathrm{Jam}$ & $\begin{array}{c}\text { Verifikasi } \\
\text { Peserta }\end{array}$ & Guru \\
\hline 2 & 2 Jam & $\begin{array}{l}\text { Memberikan } \\
\text { Materi dan } \\
\text { Praktek } \\
\text { Shuttle Time } \\
\text { Bulutangkis I }\end{array}$ & $\begin{array}{c}\text { Novri Gazali, } \\
\text { S.Pd.,M.Pd }\end{array}$ \\
\hline 3 & 2 Jam & $\begin{array}{l}\text { Memberikan } \\
\text { Materi dan } \\
\text { Praktek } \\
\text { Shuttle Time } \\
\text { Bulutangkis II }\end{array}$ & $\begin{array}{c}\text { Novri Gazali, } \\
\text { S.Pd.,M.Pd }\end{array}$ \\
\hline
\end{tabular}

- Kegiatan Hari Kedua

\begin{tabular}{cccc}
\hline No & Waktu & Kegiatan & Pelaksana \\
\hline \multicolumn{3}{c}{ Memberikan } \\
1 & 2 Jam & Tes & Romi Cendra, \\
& & $\begin{array}{c}\text { Keterampilan } \\
\text { Bulutangkis }\end{array}$ & S.Pd.,M.Pd
\end{tabular}

\begin{tabular}{ccc}
\hline 2 Jam & $\begin{array}{c}\text { Memberikan } \\
\text { Tes } \\
\text { Keterampilan } \\
\text { Bulutangkis }\end{array}$ & $\begin{array}{c}\text { Romi Cendra, } \\
\text { S.Pd.,M.Pd }\end{array}$ \\
\hline 1 Jam & Evaluasi & $\begin{array}{c}\text { Novri Gazali, } \\
\text { S.Pd.,M.Pd dan } \\
\text { Romi Cendra, } \\
\end{array}$ \\
& & S.Pd.,M.Pd \\
\hline
\end{tabular}

\section{HASIL DAN PEMBAHASAN}

Kegiatan pelatihan ini melibatkan Dosen Program Studi Penjaskesrek Universitas Islam Riau dan Guru Penjaskes SD Negeri 91 Rumbai Kota Pekanbaru. Selama ini di SD Negeri 91, siswanya jarang sekali bermain bulutangkis karena mereka beranggapan bermain bulutangkis itu sangat susah dan menjadi sedikit takut dan kaku dalam melakukan setiap gerakan teknik dasar bulutangkis.

Dari hasil pelatihan ini, siswa sangat antusias dan senang dalam mengikuti pelatihan shuttle time bulutangkis ini. Siswa mendengarkan dan mempraktekkan gerakan teknik dasar bulutangkis dengan baik dan benar. Sebelumnnya siswa agak canggung dalam memegang raket, setelah pelatihan siswa jadi berani dan sedikit mahir dalam bermain bulutangkis.

Pada pertemuan kedua siswa SD Negeri 91 diberikan tes keterampilan dasar bermain bulutangkis. Dari 22 orang siswa, didapati hasil tes keterampilan dasar bermain bulutangkis yaitu untuk kategori sangat baik dan baik tidak ada siswa yang memperolehnya, kategori cukup 12 orang siswa memperolehnya (54,55\%), kategori kurang 4 orang memperolehnya $(18,18 \%)$, kategori sangat kurang 6 orang memperolehnya $(27,27 \%)$. Untuk lebih jelas dapat dilihat pada tabel berikut:

Tabel 2. Hasil Keterampilan Dasar Bermain Bulutangkis

\begin{tabular}{ccccc}
\hline No & Kategori & $\begin{array}{c}\text { Kelas } \\
\text { Interval }\end{array}$ & Fa & Fr \\
\hline 1 & Sangat Baik & $>80$ & 0 & $0 \%$ \\
2 & Baik & $61-80$ & 0 & $0 \%$ \\
3 & Sedang & $41-60$ & 12 & $54.55 \%$ \\
4 & Kurang & $21-40$ & 4 & $18.18 \%$ \\
5 & Kurang Sekali & $<20$ & 6 & $27.27 \%$ \\
\hline & Jumlah & & $\mathbf{2 2}$ & $\mathbf{1 0 0 \%}$ \\
\hline
\end{tabular}

Adapun dokumentasi hasil pengabdian adalah sebagai berikut: 


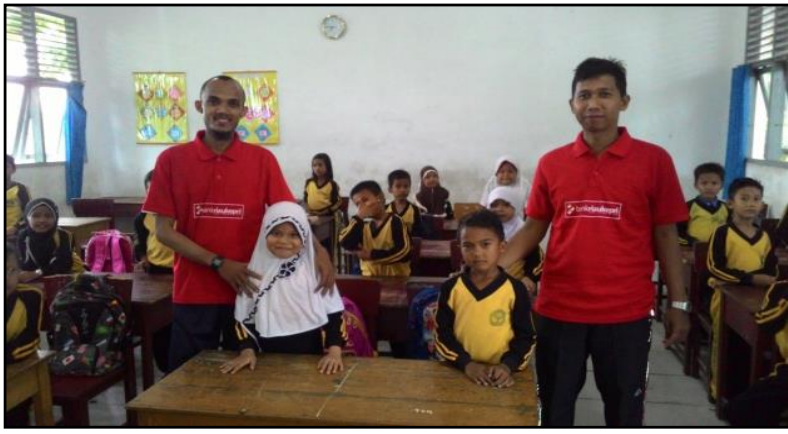

Gambar 1. Foto Bersama Siswa SD Negeri 91 Pekanbaru

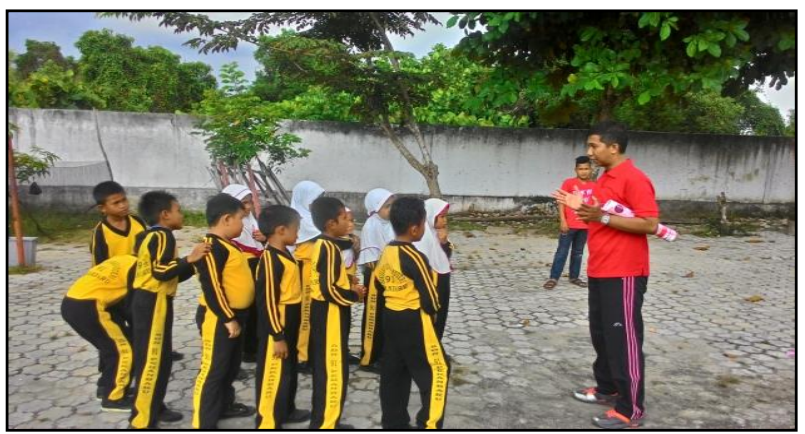

Gambar 2. Memberikan Arahan Kepada Siswa SD

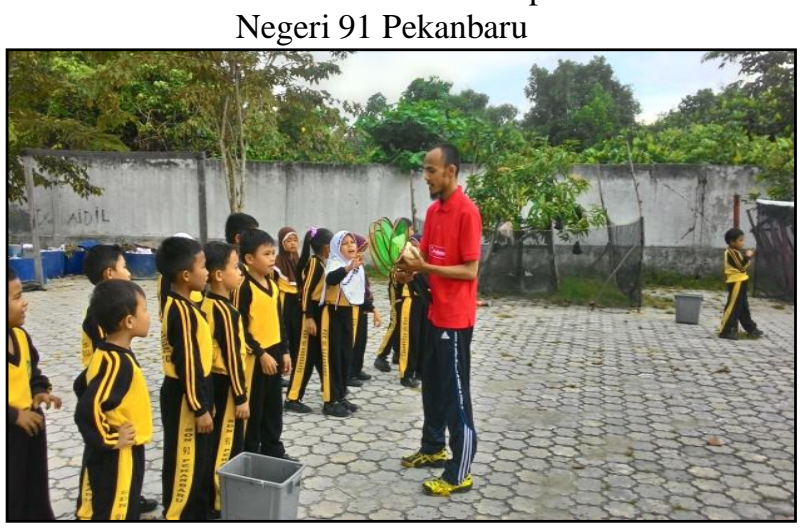

Gambar 3. Siswa SD Negeri 91 Pekanbaru Melakukan Praktek Bulutangkis

\section{KESIMPULAN}

Pelatihan yang diberikan berupa keterampilan bermain bulutangkis, membuat perencanaan pelatihan bulutangkis bagi siswa, serta mengangkat citra positif dan pengalaman menyenangkan dalam bermain bulutangkis. Diharapkan lewat program shuttle time ini, makin banyak yang mengenal dan mencintai olahraga bulutangkis. Lewat keterampilan yang dimiliki para guru sekolah dasar, mereka akan lebih mudah mengajarkan bulutangkis kepada siswanya. Secara praktis, manfaat kegiatan ini bagi guru dan siswa adalah sebagai berikut:

a. Bagi Siswa

Agar peserta didik kaya akan keterampilan dan menyukai permainan bulutangkis dengan benar.

b. Bagi Guru

Diharapkan Guru Penjaskes SD Negeri 91 Pekanbaru mendapatkan ilmu pengetahuan tentang bagaimana memberikan citra positif dalam melatih bulutangkis secara aman dan menyenangkan.

\section{UCAPAN TERIMA KASIH}

Kegiatan pengabdian masyarakat ini terlaksana atas kerjasama dengan Lembaga Pengabdian Masyarakat (LPM) Universitas Islam Riau. Kami selaku Tim pengabdian masyarakat, mengucapkan terima kasih kepada Ketua Lembaga Pengabdian Masyarakat (LPM) Universitas Islam Riau, karena telah bersedia membantu kami dalam memberikan bantuan dana selama kegiatan berlangsung. Selanjutnya kepada Kepala Sekolah dan Guru SD Negeri 91 Pekanbaru yang telah memberikan kami izin dalam kegiatan ini.

\section{DAFTAR PUSTAKA}

Abdoellah, A (1981). Olahraga Untuk Perguruan Tinggi. Yogyakarta: PT Sastra Hudaya.

Donnie. (2009). Pembinaan Bulutangkis Prestasi. Malang: PT Wineka Media.

Subarjah, H. (2001). Pendekatan Keterampilan Taktis Dalam Pembelajaran Bulutangkis. Jakarta: Departemen Pendidikan Nasional. Depdikbud.

(2001). Bulutangkis. Yogyakarta:

Yusuf, Basri. (2013). Bulutangkis Pra Level Untuk Guru Olahraga Sekolah Dasar. Jakarta: PB PBSI.

Muhajir. (2004). Pendidikan Jasmani Teori dan Praktek. Jakarta: Erlangga.

Muhajir. (2006). Pendidikan Jasmani Olahraga dan Kesehatan Untuk SMA. Jakarta: Erlangga.

Grace, T (1996). Bulutangkis. Jakarta Utara: PT. Raja Grafindo Persada. 